\title{
Investigation of Simple Electrochemical Conditions for Generation of Ozonized Water
}

\author{
Mutsumi Tanaka, Han-Joo Kim, Tae-Il Kim ${ }^{\dagger \dagger}$, and Soo-Gil Park* \\ Chungbuk National University, muttsu80@hanmail.net, \\ †PureEChem Co.Ltd., hjkim@pureechem.com, ${ }^{\dagger}$ Siontech.Co. Ltd., tikim@siontech.com
}

(Received April 11, 2008 : Accepted May 27, 2008)

\begin{abstract}
An electrochemical generation of ozonized water was investigated by using $\beta-\mathrm{PbO}_{2}$ as an anode and tap water as an anolyte. According to the potentiometric ozone detection which utilizes potential differences arisen from a chemical reaction of ozone and iodide, increasing tendency of ozone concentration on electrolysis time could be observed to show the maximum value of $8 \mathrm{ppm}$ at an electrolysis time of $10 \mathrm{~min}$. Ozone could be generated promptly even at an electrolysis time of $10 \mathrm{sec}$., suggesting great advantages of this electrochemical process in terms of simplicity and readiness that might be applied directly to practical uses including medical and/ or food industries. Influences of electrolysis on the properties and surface conditions of a $\mathrm{PbO}_{2}$ electrode were also discussed from the results of cyclic voltammetry, scanning electron microscope, and X-ray diffractometer.
\end{abstract}

Keywords : Ozonized water, Tap water, Potentiometric detection.

\section{Introduction}

Ozone, as the second strongest oxidant in natural world, is expected to play more important roles than ever before. Due to the environmentally-friendly characteristics of ozone that it naturally decomposes into oxygen at room temperature without leaving toxic residues, its application area ranges widely from domestic to industrial fields such as waste water treatment including sterilization and deodorization, bleaching, chemical syntheses, semi-conductor cleansing, and so on. Especially the usability of ozone dissolved in water (i.e., ozonized water) is good enough to be applied to practical uses directly from an ozone generating system. In terms of generation of ozonized water, an electrochemical process should be more advantageous than the conventional corona process which requires two main steps; generating ozone in the air and dissolving the generated ozone into a reagent, which implicates a significant loss of the generated ozone. Besides, an electrochemical process needs only a simple system with relatively lower applied voltage

*E-mail: sgpark@cbnu.ac.kr
$(<2 \mathrm{~V})$ to show far higher concentration of generated ozone compared with a corona process. ${ }^{1,2)}$ Experimental conditions which can be easily controlled is also one of the merits of an electrochemical process.

Theoretically, ozone generation occurs at a higher potential than competing and thermodynamically favorable oxygen evolution as below.

$$
\begin{array}{ll}
\mathrm{O}_{2}+4 \mathrm{H}^{+}+4 e^{-}=2 \mathrm{H}_{2} \mathrm{O} & E^{O}=+1.23 \mathrm{~V} \\
\mathrm{O}_{3}+6 \mathrm{H}^{+}+6 e^{-}=3 \mathrm{H}_{2} \mathrm{O} & E^{O}=+1.52 \mathrm{~V}
\end{array}
$$

And the anolyte is usually a strong acid such as $\mathrm{H}_{2} \mathrm{SO}_{4}, \mathrm{H}_{2} \mathrm{SO}_{4}$ with $\mathrm{NaF}, \mathrm{H}_{2} \mathrm{SO}_{4}$ with $\mathrm{KPF}_{6}, \mathrm{H}_{3} \mathrm{PO}_{4}$, or $\mathrm{HClO}_{4}$, regardless of the kinds of anode material. ${ }^{3-5}$ ) These severe electrochemical conditions put high demand on electrode materials to have toughness to endure the conditions as well as to have high overpotential to suppress an oxygen evolution. And this has limited the usage of various electrode materials. Although several anode materials such as boron-doped diamond, ${ }^{6,7)}$ Pt- $\mathrm{TaO}_{\mathrm{x}}$ composite, ${ }^{8,9)} \mathrm{IrO}_{2}-\mathrm{NbO}_{3}$ composite ${ }^{5)}$ have been reported, lead dioxide $\left(\beta-\mathrm{PbO}_{2}\right)$ seems to be the only practical material as an anode due to its high oxygen evolution overpotential, high resis- 
tance to corrosion, high electric conductivity, and an economical vantage. ${ }^{3,10-11)}$

Therefore, we have investigated simple and less demanding electrochemical conditions for generation of ozonized water by using a $\beta-\mathrm{PbO}_{2}$ electrode. The generation of ozonized water from simple reactants (ex. $\mathrm{H}_{2} \mathrm{O}$ ) with simple electrochemical conditions should be a promising method in the light of industry-scale ozone production in future as well as the possibility of direct usage of resultant ozonized water from a generation system. Since decomposition of ozone in water into oxygen occurs in no time, ${ }^{9)}$ an investigation of a prompt detection method for generated ozone within the time range of several minutes is also required. In this study, detection of ozone contents by using the potentiometric method ${ }^{11)}$ was also studied.

\section{Experimentals}

\subsection{Electrolysis performance}

An electrolysis cell used for generation of ozone in this study was assembled as shown in Fig. 1. Electrodes of a commercialized $\beta-\mathrm{PbO}_{2} / \mathrm{Ti}$ (Permelec Electrode Ltd.) and a laboratory-prepared $\mathrm{Pt} / \mathrm{Ti}$ were used as an anode and a cathode, respectively. The $\mathrm{PbO}_{2}$ electrode consists of $\beta$ and $\alpha$-structured $\mathrm{PbO}_{2}$ layers deposited on a Ti substrate. The platinum cathode layer was electrochemically deposited by using a Pt precursors of $\mathrm{H}_{2} \mathrm{PtCl}_{6} \cdot 6 \mathrm{H}_{2} \mathrm{O}$. ${ }^{4)}$ Tap water and $10 \mathrm{mM}$ of $\mathrm{NaCl}$

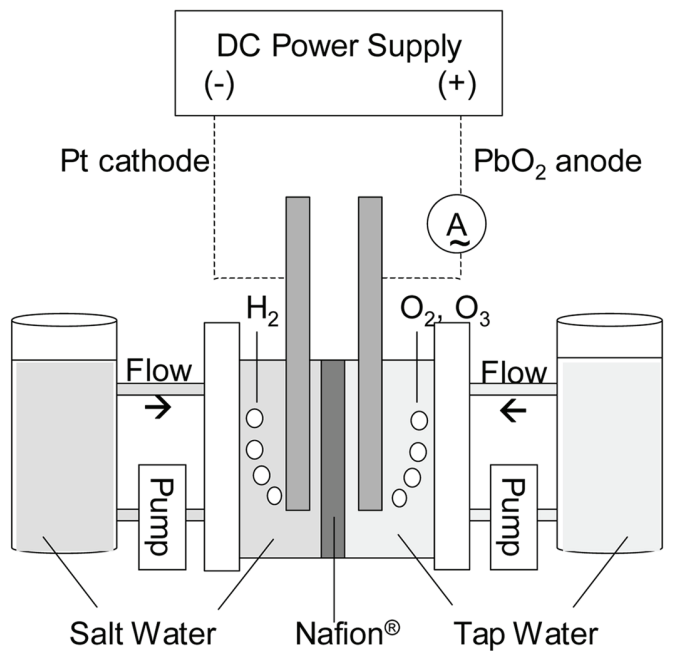

Fig. 1. Schematic diagrams of the cell assembly for generation of ozonized water.
Table 1. Electrolysis conditions

\begin{tabular}{lc}
\hline Conditions & Value \\
\hline Applied voltage $[\mathrm{V}]$ & 2.0 \\
Electrolysis Duration $[\mathrm{S}]$ & $0 \sim 1800$ \\
Cell system temperature $\left[{ }^{\circ} \mathrm{C}\right]$ & r.t. \\
Electrolyte Flow Rate $[\mathrm{mL} / \mathrm{s}]$ & 10 \\
\hline
\end{tabular}

salt water were used as an anolyte and a catholyte, and Nafion ${ }^{\circledR} 324$ (DuPont) was used as a protonexchange membrane. Salt water acted as an electric conductor, and tap water was chosen in hope of a direct application to practical uses in future. There is also a report which uses imitation tap water with a $\mathrm{Pt}-\mathrm{TaO}_{\mathrm{x}}$ composite electrode [8], and the main chemical reactions at the interface between a $\beta-\mathrm{PbO}_{2}$ electrode and an electrolyte can be expressed as in Eqs. (1) and (2).

The electrolysis conditions are shown in Table 1 Voltage of 2.0 was applied while both electrolytes were circulated by pump throughout the electrolysis. The electrolysis duration was varied from 0 to 1800 seconds. Experiments were done under room temperature and the flow rate of both electrolyses was $10 \mathrm{~mL} / \mathrm{s}$.

\subsection{Ozone detection by electrochemical method}

Potentiometric measurements were performed at room temperature by using a potentiostat (IviumStat, Ivium Technologies Co.). Platinum wires were used as working and counter electrodes, and an $\mathrm{Ag} / \mathrm{AgCl}_{2}$ (sat. $\mathrm{KCl}$ ) electrode was used as a reference electrode. These three electrodes were well separated by a threeneck flask and a salt bridge. A potential buffer solution was prepared to have known-concentrations with $10 \mathrm{mM}$ of $\mathrm{I}^{-}$and $1 \mathrm{mM}^{\circ} \mathrm{I}_{3}{ }^{-11)}$ by adding a potassium iodine $(\mathrm{KI})$ and an iodine $\left(\mathrm{I}_{2}\right)$ volumetric solution into a standard buffer solution $(\mathrm{pH}=4.0)$. An open circuit potential of the working electrode put into the prepared buffer solution was recorded in order to obtain the potential difference of before and after the introduction of generated ozonized water into the buffer solution. All detections of generated ozone were performed within a minute after the completion of the electrolysis.

According to the T. Ohsaka, ${ }^{11)}$ the introduction of ozonized water into the buffer solution with $\mathrm{I}^{-}$and $\mathrm{I}_{3}^{-}$promotes the oxidation of the iodide ion, resulting in potential differences. The potential change on the working electrode measured by an open circuit potential could be used for the calculation of ozone 
contents as follows.

From the Nernst equation at $25^{\circ} \mathrm{C}$, the following simplified equation was proposed for the calculation of oxidant concentration when $\left[\mathrm{I}^{-}\right]_{\mathrm{o}}$ " $[\mathrm{Ox}]$ and $\left[\mathrm{I}_{3}^{-}\right]_{\mathrm{o}}$ $[\mathrm{Ox}]{ }^{11)}$

$$
\Delta E=13.0\left([O x] /\left[I_{3}^{-}\right]_{0}\right)
$$

Where $\left[\mathrm{I}^{-}\right]_{\mathrm{o}}$ and $\left[\mathrm{I}_{3}^{-}\right]_{\mathrm{o}}$ are initial concentrations of $\mathrm{I}^{-}$and $\mathrm{I}_{3}^{-}$ions and [Ox] is the concentration of generated ozone. Although there are three kinds of calculation equations depending on the value of $\left[\mathrm{I}^{-}\right]_{\mathrm{o}}$, $\left[\mathrm{I}_{3}{ }^{-}\right]_{\mathrm{o}}$, and $[\mathrm{Ox}]$, the Eq. (3) was chosen in this study since the concentration of each iodide ion is projected to be $10 \mathrm{mM}$ of $\mathrm{I}^{-}$and $1 \mathrm{mM}^{\text {of } \mathrm{I}_{3}}{ }^{-}$, respectively while that of ozone is speculated to be in the range of $0.02 \sim 0.2 \mathrm{mM}(1 \sim 10 \mathrm{ppm})$ from our past investigations using an ozone detector equipment.

\subsection{Cyclic Voltammetry}

Cyclic Voltammetry was performed by using a potentiostat (Ivium Technologies Co.) to observe redox reactions on a $\beta-\mathrm{PbO}_{2} / \mathrm{Ti}$ electrode. A Pt electrode put into $0.5 \mathrm{M}-\mathrm{H}_{2} \mathrm{SO}_{4}$ aq. was used as a working electrode, $\mathrm{An} \mathrm{Ag} / \mathrm{AgCl}_{2}$ (sat. $\mathrm{KCl}$ ) as a reference electrode, and a $\mathrm{Pt} / \mathrm{Ti}$ meshed plate as a counter electrode, respectively. Scanning was performed in the range of 0 to $3 \mathrm{~V}$ at a scanning rate of $50 \mathrm{mV} / \mathrm{s}$ and a scanning step of $10 \mathrm{mV}$.

\subsection{Surface characterization}

Surface morphology of a $\beta-\mathrm{PbO}_{2}$ electrode before and after the electrolysis was observed by using a scanning electron microscope (SEM, HITACHI S2500C). The magnitude was $15.00 \mathrm{~K}$, the extra high tension (EHT) was $5 \mathrm{kV}$, and the working distance (WD) was $3 \mathrm{~mm}$. Microstructure of the $\mathrm{PbO}_{2}$ electrode surface was analyzed by using a X-ray diffractometer (XRD, Bruker AXS, D8 DISCOVER) with $\mathrm{Cu}-\mathrm{K} \alpha$ radiation.

\section{Results and Discussion}

\subsection{Generation of ozonized water}

By utilizing the electrolysis cell shown in Fig. 1, the possibility of ozone generation was checked with a commercialized ozone detector (Ai denshi kogyo Co. AOM-05). As seen in Table 2, ozone was successfully generated from drinking tap water. Although the detectable concentration of ozone by the detector is rough with the minimum scale of
Table 2. Ozone concentrations of ozonized water

\begin{tabular}{cc}
\hline Electrolysis time $[\mathrm{S}]$ & Concentration [ppm] \\
\hline 30 & ca. 2.5 \\
60 & $>5.0$ \\
600 & $>5.0$ \\
\hline
\end{tabular}

$0.5 \mathrm{ppm}$, high concentration of more than $5 \mathrm{ppm}$ could be obtained when the electrolysis duration is over $1 \mathrm{~min}$. Remarkably, relatively high concentration of ca. $2.5 \mathrm{ppm}$ was also obtained even with the electrolysis duration of as short as $30 \mathrm{sec}$. This readiness of ozone generation as well as the usage of tap water should be noted as great advantages of this electrochemical process for future application, revealing the resultant of ozonized water can be applied to a practical use directly from a generator. Although the mechanism of ozone generation on a $\mathrm{PbO}_{2}$ electrode has yet to been clarified, it has been reported that the existence of an adsorbed radical oxygen $\left(O^{*}\right)$ acts as an active part. ${ }^{10)}$

$$
\begin{aligned}
& \left(\mathrm{H}_{2} \mathrm{O}\right)_{a d s} \rightarrow\left(\mathrm{OH}^{\bullet}\right)_{a d s}+\mathrm{H}^{+}+e^{-} \\
& \left(\mathrm{OH}^{*}\right)_{a d s} \rightarrow\left(\mathrm{O}^{*}\right)_{a d s}+H^{+}+e^{-} \\
& \left(2 \mathrm{O}^{*}\right)_{a d s} \rightarrow\left(\mathrm{O}_{2}\right)_{a d s} \\
& \text { or }\left(\mathrm{O}^{*}\right)_{a d s}+\left(\mathrm{O}_{2}\right)_{a d s} \rightarrow\left(\mathrm{O}_{3}\right)_{a d s} \\
& \left(\mathrm{O}_{2}\right)_{a d s} \rightarrow \mathrm{O}_{2} \uparrow \\
& \text { or }\left(\mathrm{O}_{3}\right)_{a d s} \rightarrow \mathrm{O}_{3} \uparrow
\end{aligned}
$$

According to this mechanism, the adsorbed oxygen $\left(\left(\mathrm{O}_{2}\right)_{\text {ads }}\right)$ seems to be required while only the evolution to oxygen gas (Eq. (8)) should be blocked for an effective ozone generation.

\subsection{Potentiometric detection of generated ozone}

In the light of prompt and accurate detection of the generated ozonized water, an electrochemical process should be advantageous because chemical reactions occur in no time and gap of the electrochemical potential from the reaction is minute in unit of $\mathrm{mV}$. The reaction between ozone and iodine is well known as written in the past patent [12], and they react in compliance with the Eq. (10).

$$
2 \mathrm{KI}+\mathrm{O}_{3}+\mathrm{H}_{2} \mathrm{O} \rightarrow 2 \mathrm{KOH}+\mathrm{I}_{2}+\mathrm{O}_{2}
$$

And the reaction of $\mathrm{I}_{2} / \mathrm{I}^{-}$redox electrode was reported to show the following equation (Eq. (11)) 


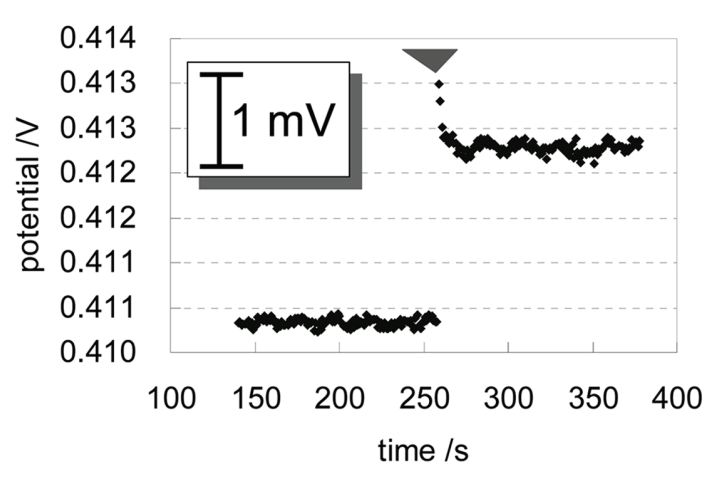

Fig. 2. Example of the potential gap from an open circuit potential obtained by introduction of generated ozonized water into the buffer solution (electrolysis duration $=30$ s. at r.t.). A triangle mark indicates the timing when the ozonized water was added.

in the presence of an excess of $\mathrm{I}^{-}$to $\mathrm{I}_{2}{ }^{11)}$

$$
3 I^{-}=I_{3}^{-}+2 e^{-}
$$

Fig. 2 shows an example of the potential gap obtained from an open circuit potential measurement. The potential gap arisen from an addition of the ozonized water into the iodine buffer solution was seen regardless of electrolysis duration in the range of $10 \sim 1800 \mathrm{sec}$. Fig. 3 is the tendency of ozone concentration which was calculated from the Eq. (3) and the potential gap in Fig. 2. Ozone could be detected even at short electrolysis duration of $10 \mathrm{sec}$ and its concentration increased slightly as the electrolysis continued. The value of maximum concentration we could obtain was $8.8 \mathrm{ppm}$ at $10 \mathrm{~min}$

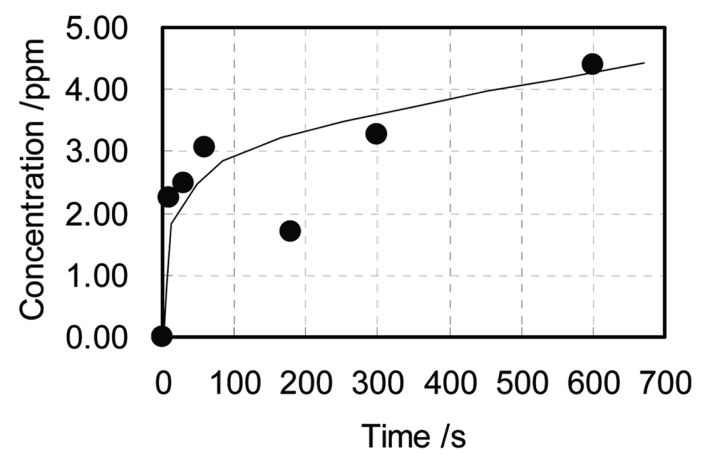

Fig. 3. Tendency of ozone concentration on the electrolysis duration at r.t. and flow rate of $8 \mathrm{~mL} / \mathrm{s}$, ozone was detected by a potentiometric analysis. All data were corrected by subtracting the value at where electrolysis time equals to 0 . of the electrolysis. By comparing the ozone concentration directly obtained from the potentiometric method (not shown in this paper) with that from an ozone detector (Table 2), the concentration were loosely accordant to show the value of over $5 \mathrm{ppm}$ when the electrolysis duration was over $1 \mathrm{~min}$.

However, as can be seen in Fig. 3, the fluctuation of the potential graph which is relatively large compared with the measurement scale undermines the accuracy of this electrochemical measurement. Furthermore, the potential gap of ca. $0.8 \mathrm{mV}$ was obtained with addition of tap water, which is not negligible. According to Eq. (10), the evolution of oxygen and hydroxide ion $\left(\mathrm{OH}^{-}\right)$occurs as a result of oxidation by ozone. However, this reaction seems to be able to happen when whatever the oxidant was introduced. The cause of the potential gap with introduction of tap water is yet to be cleared, but instead of ozone, chloride ion $\left(\mathrm{Cl}^{-}\right)$which naturally exists in drinking water might act as an oxidant.

$$
2 \mathrm{KI}+\mathrm{Cl}_{2} \rightarrow 2 \mathrm{KCl}+\mathrm{I}_{2}
$$

Therefore, the value of potential gap at where no electrolysis was operated should always be subtracted from each datum in order to obtain reliable plots.

One thing to be noticed is that all potentiometric detections in this study were performed within a minute, indicating that this electrochemical measurement is suitable for ozone detection in terms of readiness.

\subsection{Cyclic Voltammetry}

Cyclic voltammograms of a $\beta-\mathrm{PbO}_{2}$ electrode were shown in Fig. 4 in the applied potential range

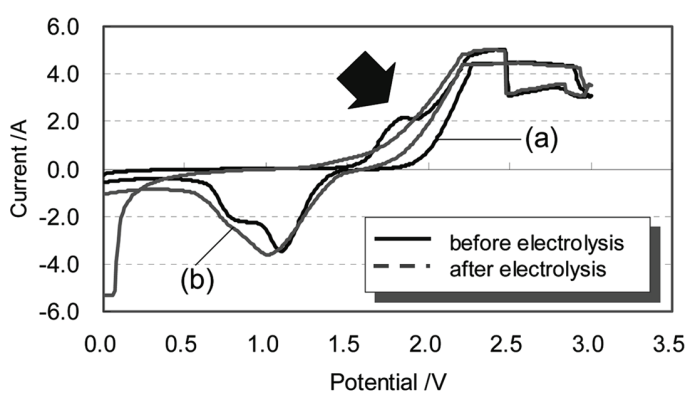

Fig. 4. Cyclic voltammograms obtained with a $\mathrm{PbO}_{2}$ electrode in $0.5 \mathrm{M}-\mathrm{H}_{2} \mathrm{SO}_{4}$ aq., (a) before electrolysis and (b) after ca. 30 hours of electrolysis, respectively. An arrow shows a peak attributes to $\mathrm{O}_{2}$ and $\mathrm{O}_{3}$ evolutions. 
of 0 to $3 \mathrm{~V}$ in order to observe the change in redox reactions on a $\mathrm{PbO}_{2}$ electrode before and after several electrolysis operations. In both Fig. 4 (a) and (b), large cathodic peaks are seen at ca. $+1.2 \mathrm{~V}$ indicating the reduction of $\mathrm{PbO}_{2}$ (IV) to $\mathrm{PbSO}_{4}$ (II) (Eq. (13)) as well as large anodic peaks at over ca. $+2.0 \mathrm{~V}$ indicating the recovery of $\mathrm{PbO}_{2}$ by the oxidation of $\mathrm{PbSO}_{4}$ formed during the cyclic voltammogram performance (Eq .(14)). It was reported that when cycled in a sulfuric acid, $\mathrm{PbSO}_{4}$ was oxidized to give preferably $\beta-\mathrm{PbO}_{2}$ according to Eq. (14) rather than $\alpha$ $\mathrm{PbO}_{2}$, changing the composition of $\alpha / \beta-\mathrm{PbO}_{2}{ }^{13)}$

$$
\begin{aligned}
& \alpha / \beta-\mathrm{PbO}_{2}+4 \mathrm{H}^{+}+\mathrm{SO}_{4}{ }^{2-}+2 e^{-} \\
& \rightarrow \mathrm{PbSO}_{4}+2 \mathrm{H}_{2} \mathrm{O} \\
& \mathrm{PbSO}_{4}+2 \mathrm{H}_{2} \mathrm{O} \\
& \rightarrow \mathrm{\beta}_{-} \mathrm{PbO}_{2}+4 \mathrm{H}^{+}+\mathrm{SO}_{4}{ }^{2-}+2 e^{-}
\end{aligned}
$$

Another remarkable point is that the broad peak at ca. $+1.8 \mathrm{~V}$ which attributes to the oxygen and ozone evolutions (see the arrow in Fig. 4 (a)) has disappeared after about 30 hours of electrolysis in total, suggesting that the surface of $\mathrm{PbO}_{2}$ has lost its catalytic characterization for ozone generation.

\subsection{Surface characterization}

In order to investigate the cause of the deterioration of a $\mathrm{PbO}_{2}$ electrode observed in the cyclic voltammogram, a plane image of SEM was taken. Fig. 5 shows plane images of the surface of the $\mathrm{PbO}_{2}$ electrode before (a) and after (b) the 30 hours of electrolysis in total. From SEM images, a drastic change in the surface morphology after the electrolysis can be seen with apparently higher surface roughness, larger agglomerates (size of $>1 \mu \mathrm{m}$ ), and acicular materials. Therefore, the deterioration of a $\mathrm{PbO}_{2}$ electrode on the
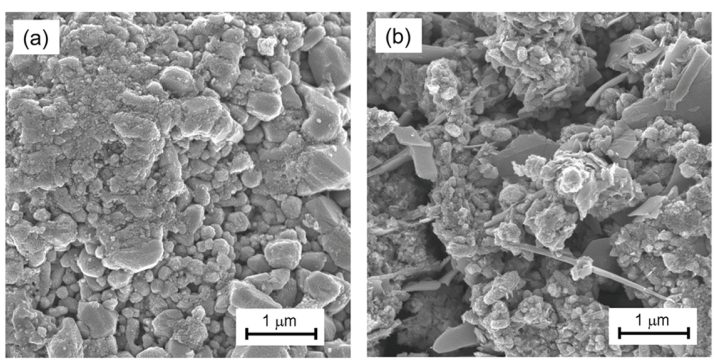

Fig. 5. Plane SEM images of a $\mathrm{PbO}_{2}$ electrode surface, (a) before electrolysis and (b) after ca. 30 hours of electrolysis, respectively. electrolysis seemed to attribute to the formation of impurities which interferes the catalytic property of a $\mathrm{PbO}_{2}$ electrode. The color of the $\mathrm{PbO}_{2}$ electrode surface has also changed apparently from dark grey to a mixture of brown and white. It was impossible to completely clean up the changed color by using $0.1 \mathrm{M}-\mathrm{HCl}$ aq. together with ultrasonication for several times. Although further investigation to identify the impurities is needed, the natural reduction of $\mathrm{PbO}_{2}$ to $\alpha-\mathrm{PbO}$ of red color (Eq. (15)), the formation of $\mathrm{Pb}_{4}(\mathrm{OH})_{4}\left(\mathrm{ClO}_{4}\right)_{4}\left(\mathrm{H}_{2} \mathrm{O}\right)_{2}$ of grey color from $\mathrm{Cl}^{-}$ion in tap water, and the formation of $\mathrm{PbSO}_{4}$ of white color (Eq. (13)) are among strong possibilities of the impurities.

$$
2 \alpha / \beta-\mathrm{PbO}_{2} \rightarrow 2 \alpha-\mathrm{PbO}+\mathrm{O}_{2}
$$

Fig. 6 shows XRD patterns of a $\mathrm{PbO}_{2}$ electrode before (a) and after (b) the hours of electrolysis. As seen in Fig. 6, most of peaks are attributed to a or $\beta$-structured lead dioxide in accordance with the composition of the commercialized $\mathrm{PbO}_{2}$ electrode. However, there are some peaks (indicated as circle marks) observed for the $\mathrm{PbO}_{2}$ electrode only after hours of the electrolysis. From the JCPDS data, these peaks are well in agreement with those of lead sulfate $\left(\mathrm{PbSO}_{4}\right.$, where strong peaks appear at $2 \theta=29.6^{\circ}, 43.6^{\circ}, 44.4^{\circ}$, and $\left.45.8^{\circ}\right)$. It is possible to assume that considerable amount of $\mathrm{PbSO}_{4}$ was formed onto the $\mathrm{PbO}_{2}$ electrode when $\mathrm{H}_{2} \mathrm{SO}_{4}$ solution was utilized as an anolyte for the electrolysis (data are not shown in this paper) and/or as an electrolyte for

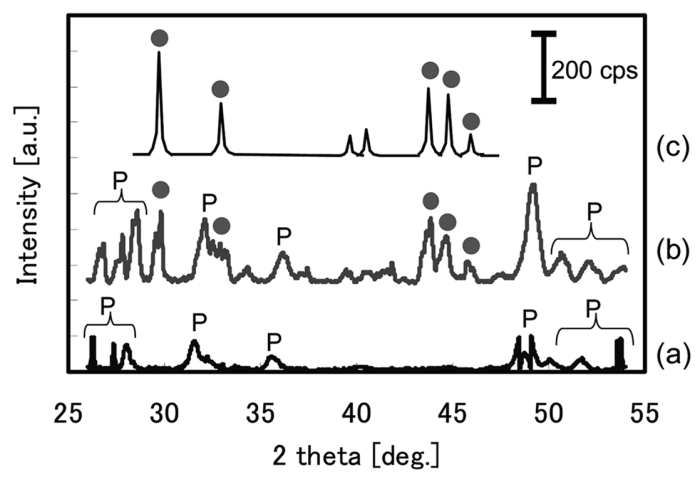

Fig. 6. XRD Patterns of a $\mathrm{PbO}_{2}$ anode (a) before and (b) after hours of electrolysis, where $P$ is attributed to either $\alpha$ $\mathrm{PbO}_{2}$ or $\beta-\mathrm{PbO}_{2}$, and circle marks (•) to $\mathrm{PbSO}_{4}$, respectively. The image patterns of $\mathrm{PbSO}_{4}$ (c) was also included. 
a cyclic voltammetry experiment. Therefore, the cause of the deterioration in the overpotential characteristics of the $\mathrm{PbO}_{2}$ electrode seems to be due to the existence of $\mathrm{PbSO}_{4}$ on the electrode surface and it is essential to remove this impurity for achieving more stable ozone generation.

\section{Conclusions}

Ozonized water was successfully generated from drinking tap water and salt water with a $\beta-\mathrm{PbO}_{2}$ electrode. From the potentiometric ozone detection which uses the potential gap arisen from a chemical reaction of ozone and iodide ion, increasing tendency of the ozone concentration on the electrolysis duration was observed to give the maximum value of $8.8 \mathrm{ppm}$ when the electrolysis duration was $10 \mathrm{~min}$. And also, ozone could be readily generated even at the electrolysis duration of $10 \mathrm{sec}$. This readiness of ozone generation as well as the simplicity of using tap water and salt water is a great advantage of the electrochemical process in this study, suggesting the resultant ozonized water could be applied to the future practical use directly from a generator.

It should be noticed that the potentiometric analysis in this study could detect ozone contents within a minute, revealing the method to be suitable for ozone detection. However, relatively high fluctuation of the calculated ozone concentration and the existence of potential gap with addition of just tap water undermined the accuracy of this electrochemical measurement. Cyclic voltammograms indicated the vulnerable catalytic property of a $\beta-\mathrm{PbO}_{2}$ electrode with showing no oxidation peak contributing to ozone generation after about 30 hours of electrolysis. The cause of the degradation seems to be the existence of $\mathrm{PbSO}_{4}$ formed onto the electrode surface.

\section{References}

1. P. C. Foller and G. H. Kelsall, 'Ozone generation via the electrolysis of fluoboric acid using glassy carbon anodes and air depolarized cathodes' J. Appl. Electrochem., 23, 996 (1993).

2. S. Stucki, G. Theis, R. Kotz, H. Devantay, and H. J. Christen, 'In situ production of ozone in water using a membrel electrolyzer' J. Electrochem. Soc., Feb. 367 (1985).

3. E. R. Kotz and S. Stucki, 'Ozone and Oxygen evolution on $\mathrm{PbO}_{2}$ electrodes in acid solution' J. Electroanal Chem., 228, 407 (1987).

4. M. I. Awad, S. Sata, K. Kaneda, M. Ikematsu, T. Okajima, and T. Ohsaka, 'Ozone electrogeneration at a high current efficiency using a tantalum oxide-platinum composite electrode' Electrochem. Comm., 8, 1263 (2006).

5. M. H. P. Santana, L. A. De Faria, and J. F. C. Boodts, 'Investigation of the properties of $\mathrm{Ti} /\left[\mathrm{IrO}_{2}-\mathrm{Nb}_{2} \mathrm{O}_{5}\right]$ electrodes for simultaneous oxygen evolution and electrochemical ozone production, EOP' Electrochim. Acta., 49, 1925 (2004).

6. N. Katsuki, E. Takahashi, M. Toyoda, T. Kurosu, M. Iida, S. Wakita, Y. Nishiki, and T. Shimamune, 'Water electrolysis using diamond thin-film electrodes' $J$. Electrochem. Soc., 145, 2358 (1998).

7. S. G. Park, G. S. Kim, J. E. Park, Y. Einaga, and A. Fujishima, 'Use of Boron-Doped Diamond Electrode in Ozone Generation' J. New. Mat. Electrochem. Systems, 8, 65 (2005).

8. K. Kaneda, M. Ikematsu, Y. Koizumi, H. Minoshima, T. Rakuma, D. Takaoka, and M. Yasuda, 'Ozone generation by a $\mathrm{TaO}_{\mathrm{x}}$ and Pt Composite Insulator-coated Ti electrode' Electrochem. Solid State Lett., 8, J13 (2005).

9. M. O. Buffle, J. Schumacher, E. Salhi, M. Jekel, and U. Gunten, 'Measurement of the initial phase of ozone decomposition in water and wastewater by means of a continuous quench-flow system' Water Research 40, 1884 (2006).

10. L. M. Da Silva, L. A. De Faria, and J. F. C. Boodts, 'Green process for environmental application. Electrochemical ozone production' Pure Appl. Chem., 73, 1871 (2001).

11. M. I. Awad and Takeo Ohsaka, 'Potentiometric analysis of peroxyacetic acid in the presence of a large excess of hydrogen peroxide' J. Electroanal. Chem. 544, 35 (2003).

12. W. D. Komhyr, 'Method of sensing the ozone in upper atmosphere' US Patent 3428542 (1969).

13. D. Devilliers, M. T. Dinh Thi, E. Mache, V. Dauriac, and N. Lequeux, 'Electroanalytical investigations on electrodeposited lead dioxide' J. Electroanal. Chem. 573, 227 (2004). 